\title{
A MICRO DIRECT METHANOL FUEL CELL WITH SELF-PUMPING OF LIQUID FUEL
}

\author{
Dennis Desheng Meng" and Chang-Jin "CJ" Kim \\ Mechanical and Aerospace Engineering Department, University of California, Los Angeles (UCLA) \\ Los Angeles, CA, U.S.A.
}

\begin{abstract}
This paper introduces a micro direct methanol fuel cell ( $\mu$ DMFC) with an imbedded self-pumping mechanism to deliver liquid fuel. The fuel is propelled without any power consuming component (e.g., a pump), while removing the $\mathrm{CO}_{2}$ bubbles generated by the fuel-cell electrochemical reaction of the system. Furthermore, the pumping rate is self-regulated by the reaction, i.e., by the load. By eliminating the need for a pump and gas/liquid separator, our design allows much simpler systems, which is especially beneficial for miniaturization. Although we test with $\mu \mathrm{DMFC}$ in this paper, the mechanism applies to other hydrocarbon liquid fuels as well.
\end{abstract}

\section{INTRODUCTION}

Due to its much higher energy density than traditional batteries, micro direct methanol fuel cell ( $\mu$ DMFC) has been widely considered as the next generation power source for portable electronic devices. $\mu \mathrm{DMFC}$ has been anticipated to be one of the first fuel cells to fully enter the consumer market in the near future [1], with a few products already announced [2-4]. However, several technical hurdles still need to be cleared to make the $\mu \mathrm{DMFC}$ mature and finally accepted by the consumer market, including the cost, the performance of membrane electrode assembly (MEA), and the complexity compared with traditional batteries.

The working principle of $\mu \mathrm{DMFC}$ is illustrated in Fig. 1 . The aqueous methanol solution is fed into the anodic channel while air flows through the cathodal channel. A series of electrochemical reactions are enabled by the proton exchange membrane (PEM) and the catalyst layers. Protons migrate from anode to cathode through the PEM, while electrons are collected by the anodic electrode and consumed in the cathodal electrode. The accumulated electrons provide the continuous current for the external circuit. An external pump is usually used to provide a continuous flow of methanol fuel to the anode and maintain the fuel concentration there.

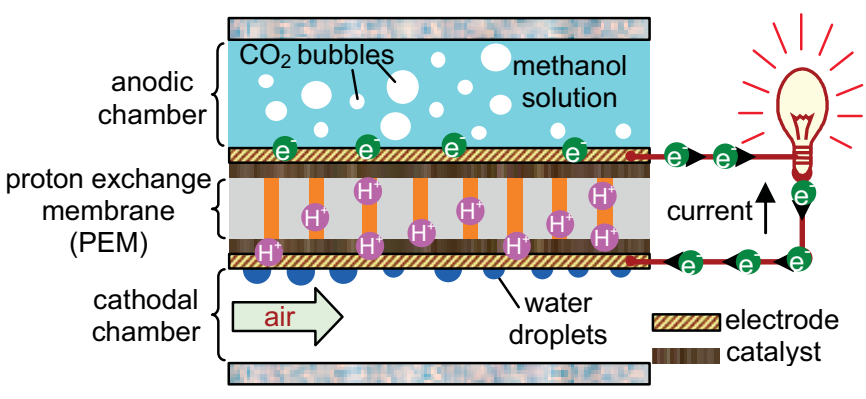

Figure 1. Working principle of direct methanol fuel cell
In the fuel stack of a DMFC, the electrochemical reactions are:

$$
\begin{array}{lr}
\mathrm{CH}_{3} \mathrm{OH}+\mathrm{H}_{2} \mathrm{O} \rightarrow 6 e^{-}+6 \mathrm{H}^{+}+\mathrm{CO}_{2} \uparrow, & \text { (anode side) } \\
1.5 \mathrm{O}_{2}+6 e^{-}+6 \mathrm{H}^{+} \rightarrow 3 \mathrm{H}_{2} \mathrm{O}, & \text { (cathode side) } \\
\mathrm{CH}_{3} \mathrm{OH}+1.5 \mathrm{O}_{2} \rightarrow 2 \mathrm{H}_{2} \mathrm{O}+\mathrm{CO} \uparrow . & \text { (overall reaction) }
\end{array}
$$

According to this reaction, $\mu \mathrm{DMFCs}$ intrinsically generate $\mathrm{CO}_{2}$ gas bubbles. If not promptly removed, these bubbles will clog the anodic microchannels and aggravate the deleterious methanol crossover. The current common practice is to use an external pump to deliver the fuel and push the gas bubbles to downstream at the same time. Then an open tank (gas/liquid separator) can be used to release $\mathrm{CO}_{2}$ gas [5]. This approach is impractical in a portable device because of the danger of fuel leakage. Meanwhile, using an external pump to deliver fuel not only takes up a space and complicates the microsystem, but also claims a significant portion of the power output of $\mu$ DMFC. Since most reported micropumps require $100 \mathrm{~mW}$ or higher of power input, about $10 \%$ of the fuel cell total power output (usually $\sim 1 \mathrm{~W}$ ) has to be consumed by pumping. This percentage can be even higher if the fuel cell is not working at the maximum power capability.

We have previously proved that nanoporous membrane can remove gas bubbles while holding liquid with satisfactory pressure tolerance [6]. Combined with virtual check valves, the venting mechanism has also enabled a new bubble-driven pumping mechanism. The gas bubbles generated by electrolysis were employed to circulate $\mathrm{Na}_{2} \mathrm{SO}_{4}$ aqueous solution in a microfluidic loop [7].

In this paper, a similar pumping mechanism is applied to a $\mu \mathrm{DMFC}$, with the intrinsically generated $\mathrm{CO}_{2}$ gas bubbles as the gas source. Therefore, the fuel delivery requires no power input at all. The design solves the bubble clogging and fuel delivery problems at the same time. Both the gas/liquid separator and external pump are eliminated from the system, allowing an integrated, simply and economic design of $\mu \mathrm{DMFC}$ system.

\section{HYDROPHOBIC VENTING}

The gas removal approach is implemented by microscopic hydrophobic (or lyophobic for methanol) venting holes, which allow the gas to pass through relatively undeterred while the liquid menisci blocks the liquid from flowing out. Fig. 2 represents an idealized model to illustrate how liquid can be restricted from leaking by its own meniscus. On the sharp corner of the venting hole's entrance, this meniscus can assume a range of curvatures, so as to balance with the varying pressure across the meniscus (transmeniscus pressure) according to the Laplace-Young equation:

$$
P_{l}-P_{o}=2 \sigma_{l} \cdot \cos (\pi-\alpha) / r,
$$

where $P_{l}$ is the pressure of the liquid fuel, $P_{o}$ is the ambient pressure, $\sigma_{l}$ is the surface tension of the liquid fuel, $\alpha$ is the angle

\footnotetext{
* Corresponding author: Dennis Desheng Meng, 37-129 Engr. IV, UCLA, CA 90095, Tel: (310)825-3977, Email: desheng@seas.ucla.edu
} 
between meniscus and the capillary wall, and $r$ is the radius of the capillary.

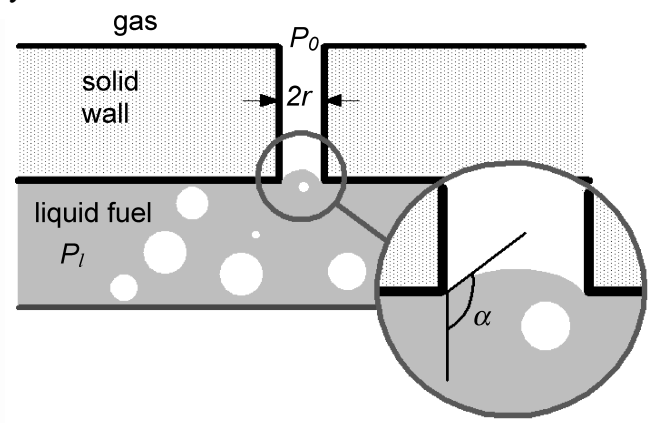

Figure 2. Hydrophobic venting by a microscopic venting hole

The maximum transmeniscus pressure that can be withstood without leakage (leakage onset pressure) is determined by the size of the venting hole as well as the surface properties associated with the hydrophobic material. Due to their intrinsic hydrophobicity and small pore size, hydrophobic nanoporous membranes can provide very high leakage onset pressure. Successful venting of gas bubbles has been achieved for both pure water and methanol fuel with a concentration as high as $10 \mathrm{M}$, by employing porous polypropylene membrane with a nominal pore radius of $0.1 \mu \mathrm{m}$ (from Chemplex ${ }^{\circledR}$ ). The fuel is proven to be contained without leakage under the over-pressures as high as $200 \mathrm{kPa}$ for both pure water and $10 \mathrm{M}$ methanol, fulfilling the requirement of the currentas well as next-generation $\mu \mathrm{DMFC}[8]$.

\section{PUMPING BY HYDROPHOBIC VENTING}

A new bubble-driven pumping mechanism [9] has been developed utilizing hydrophobic venting, as Fig. 3 illustrates. A group of small hydrophilic capillaries are fabricated on the left side of the bubble source to serve as a virtual check valve for gas bubbles. When a bubble grows at a location close to this virtual check valve (as Fig. 3-a shows), expansion of the left menisci of the bubble is hindered due to its capability to provide higher capillary pressure than the right meniscus does. Consequently, the bubble only grows to the right and pushes the liquid rightward. The bubbles generated in the middle of the microchannel can be pushed by the leftmost one to the right. This rightward bubble motion can also be promoted by proper design of the channel shape, e.g., a diverging hydrophilic shape [10]. By making the microchannel hydrophilic (e.g., $\mathrm{SiO}_{2}$ ), a surface energy difference between its hydrophilic surface and the hydrophobic membrane can make the latter a "bubble trap" [11]. Once a bubble reaches the hydrophobic nanoporous membrane, it will be drawn into the membrane region (Fig. 3-b). Through the venting holes in the membrane, the bubble is vented out without liquid loss. The liquid then fills into the section symmetrically to replace the vacancy left by the gas bubble. A pumping cycle is thus completed and a net pumping to the right is achieved.

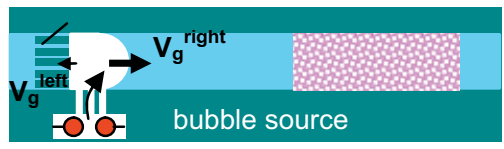

a. Directional bubble growth

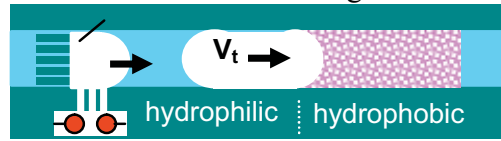

b. Built-in bubble transportation

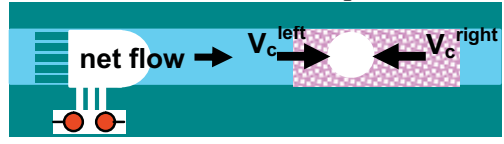

c. Symmetric bubble collapsing

Figure 3. Micropumping by directional growth and hydrophobic venting of bubbles

By using this self-pumping method, liquid circulation in a sealed closed-loop microchannel has been demonstrated by using electrolytic gas bubbles $\left(\mathrm{H}_{2}\right.$ and $\left.\mathrm{O}_{2}\right)$. By applying $2-85 \mathrm{~mW}$ power input, the liquid is circulated at a volumetric flow rate of 4.5-13.5 $\mathrm{nL} / \mathrm{s}$ in the particular pump loop. Compared with the similar thermal-bubble-driven pump, the electrochemical-bubble-driven micropump exhibits better controllability and biocompatibility with 10-100 times higher power efficiency.

\section{FABRICATION AND ACTIVATION OF $\mu$ DMFC}

In this paper, a similar pumping mechanism is applied to a $\mu \mathrm{DMFC}$, with the intrinsically generated $\mathrm{CO}_{2}$ gas bubbles as the gas source. Therefore, the fuel delivery requires no power input.

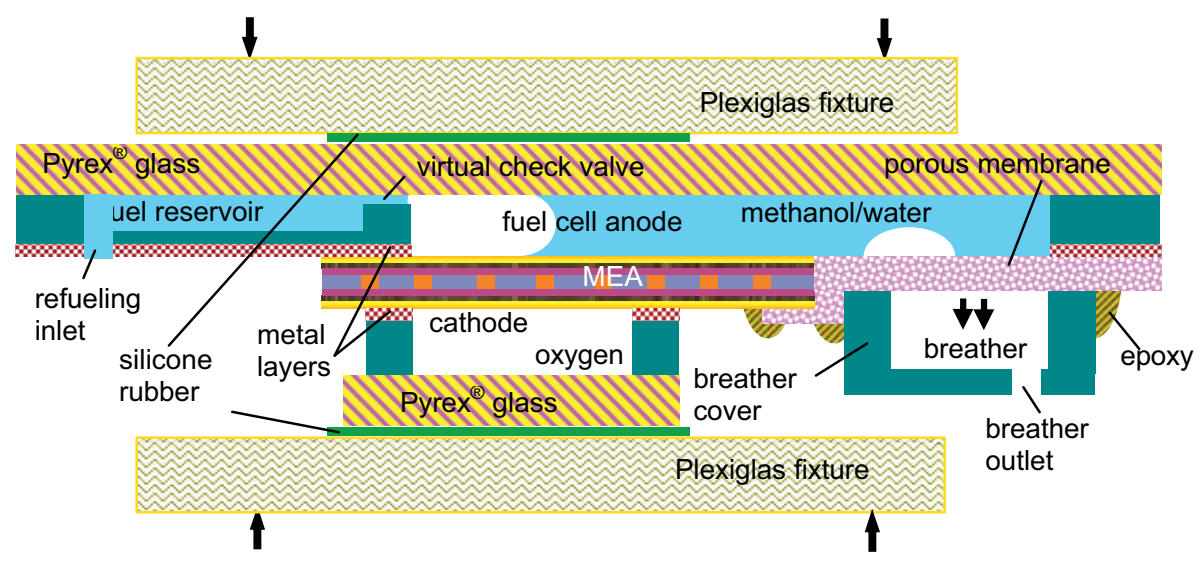

Figure 4. The cross-section of assembled self-pumping $\mu D M F C$

The cross-section of the assembled self-pumping $\mu \mathrm{DMFC}$ is shown in Fig. 4. Microchannels of the anode, the cathode and the breather cover are fabricated by DRIE, followed by metal evaporation $(0.01 \mu \mathrm{m} \mathrm{Cr}, 3 \mu \mathrm{m} \mathrm{Cu}$ and $0.5 \mu \mathrm{m} \mathrm{Au})$. The anode and 
the cathode are then anodically bonded to two pieces of Pyrex ${ }^{\circledR}$ glass. A Plexiglas fixture is used to sandwich MEA $\left(\mathrm{E}^{-T E K}{ }^{\circledR}\right)$ between the anode and the cathode. Silicone rubber sheets are added between the Plexiglas fixture and the $\mu \mathrm{DMFC}$ device to ensure uniform clamping pressure. A piece of nanoporous polypropylene film $\left(\mathrm{Chemplex}^{\circledR}\right)$ is glued between the anode and the breather cover by epoxy to remove $\mathrm{CO}_{2}$ gas bubbles during operation. The breather outlet is connected to a valve via tubing. The venting can be stopped by closing the valve to perform the control experiment. The layout of the anode microchannels, the return loop and the reservoir is shown in Fig. 5.

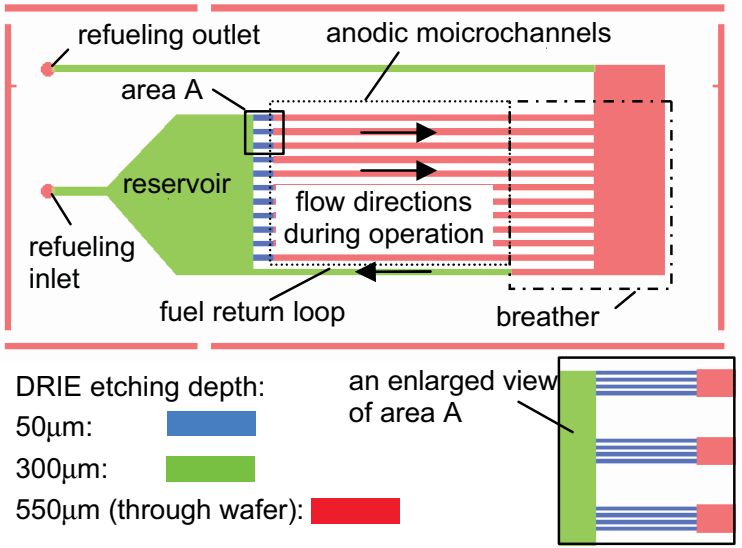

Figure 5. Layout of anodic microfluidic loop

After assembly, the MEA of the fuel cell is activated according to the procedure provided by the manufacturer. Hot DI water at $90{ }^{\circ} \mathrm{C}$ is first flowed through the anode microchannels with a flow rate of $5 \mathrm{~mL} / \mathrm{min}$ for 1.5 hours to activate the proton exchange membrane. Then, $2 \mathrm{M}$ methanol at $90{ }^{\circ} \mathrm{C}$ is flowed through the anode microchannels with a flow rate of $5 \mathrm{~mL} / \mathrm{min}$ for 3 hours. Meanwhile, oxygen is flown through the cathode channel at $\sim 100 \mathrm{~mL} / \mathrm{min}$. The cell voltage is controlled at $\sim 0.25 \mathrm{~V}$ by connecting it to a variable resistor. This second step activates the catalyst. During activation, an external pump is used to deliver the anodic liquid from the "refueling inlet" to the "refueling outlet" in Fig. 5. A pressurized gas tank is used to provide the cathodal gas flow. The measured polarization and power density curves of the $\mu \mathrm{DMFC}$ after activation are shown in Fig. 6. This test has been performed with $5 \mathrm{ml} / \mathrm{min} 2 \mathrm{M}$ methanol flow at anode, $\sim 100$ $\mathrm{ml} / \mathrm{min}$ oxygen flow at cathode and $80{ }^{\circ} \mathrm{C}$ cell temperature.

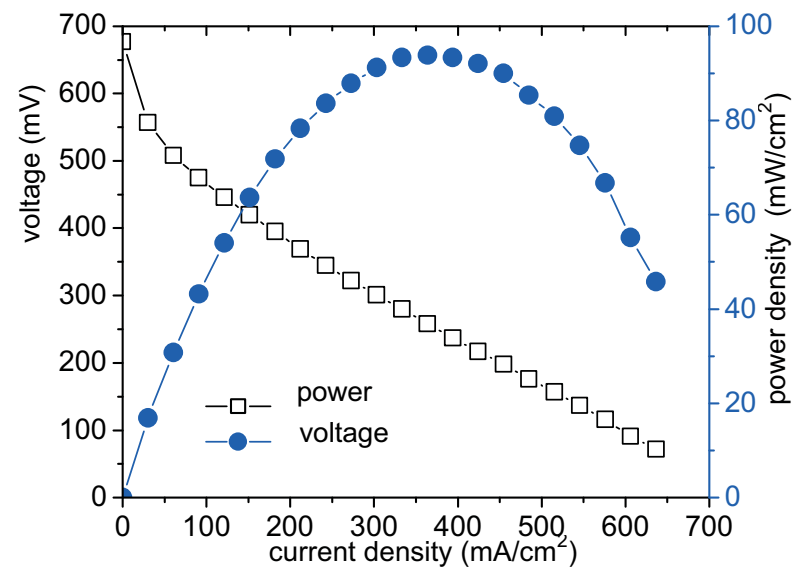

Figure 6. Polarization and power density curves of the assembled $\mu D M F C$ after MEA activation

\section{VERIFICATION OF FUEL CIRCULATION}

After activation, the fuel cell can be brought to operation condition with both the "refueling inlet" and the "refueling outlet" closed. They can be used to refuel the fuel cell if the fuel in the reservoir is used up. The gas bubbles generated by the electrochemical reaction are used as the gas source in a selfpumping mechanism to circulate the fuel, as Fig. 5 indicated. This fuel circulation mechanism does not require any external power input. Similar bubble motion pattern as in [7] has been observed throughout the flow field. Fig. 7 demonstrates the bubble motion at the end of an anodic microchannel, as well as the successful bubble removal.

$$
\begin{aligned}
& t=0 \mathrm{~s} \\
& \mathrm{t}=0.07 \mathrm{~s} \\
& \mathrm{t}=0.13 \mathrm{~s} \\
& \mathrm{t}=0.2 \mathrm{~s} \\
& \mathrm{t}=0.27 \mathrm{~s} \\
& \mathrm{t}=0.33 \mathrm{~s} \\
& \mathrm{t}=0.4 \mathrm{~s} \\
& \mathrm{t}=0.47 \mathrm{~s} \\
& \mathrm{t}=0.53 \mathrm{~s}
\end{aligned}
$$
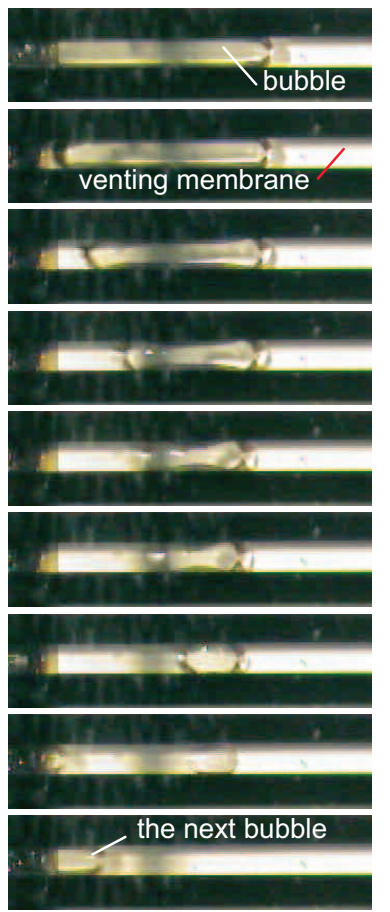

Figure 7. Bubble removal by the breather

In order to further verify the fuel circulation, the selfsustainability of the $\mu \mathrm{DMFC}$ is tested by loading the fuel cell with a $1.3 \Omega$ resister and measuring the power output over time, as shown in Fig. -8 . The self-sustainability experiments were performed under $80{ }^{\circ} \mathrm{C}$, with $2 \mathrm{M}$ methanol in the anode and $\sim 100$ $\mathrm{ml} / \mathrm{min}$ oxygen flow in the cathode. The operation time span $(\sim 8$ min) confirmed the sufficient fuel delivery, because the given reservoir is theoretically supposed to support an operation time of $\sim 9 \mathrm{~min}$ at the peak power output of this electrical load. As a reference, a control experiment was performed by closing the valve connected to the breather outlet, i.e., blocking $\mathrm{CO}_{2}$ venting and disabling the self-pumping mechanism. In the control experiment, gas bubbles were observed to grow and fill the entire anodic microchannel, and power output dropped rapidly after about 2.5 mins. Furthermore, fuel leakage was eventually observed, leading to the failure of the $\mu \mathrm{DMFC}$ device. 


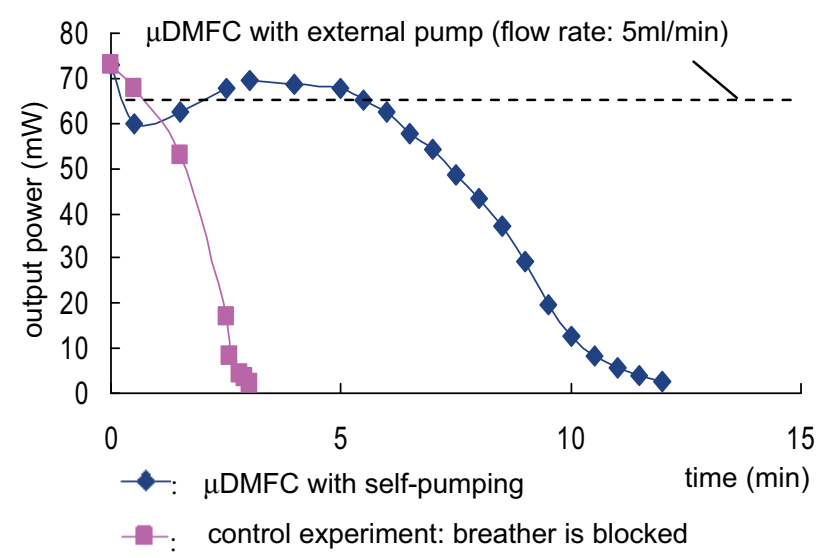

Figure 8. Self-sustainability of the self-pumping $\mu D M F C$

An interesting feature of the self-pumping is that it can be self-regulated by the reaction of $\mu \mathrm{DMFC}$. Since the bubble generation rate is directly connected to the electrochemical reaction rate, the pumping rate will increase with a faster reaction to supply fuel faster, when the external load is larger, and the pumping rate will decrease when the load is smaller.

\section{CONCLUSIONS}

A self-pumping mechanism was integrated into a $\mu \mathrm{DMFC}$ to circulate liquid fuel in the anode microchannel without any power input. By employing the directional growth of $\mathrm{CO}_{2}$ gas bubbles by the intrinsic electrochemical reaction and removing them by hydrophobic venting, a compact design of $\mu$ DMFC was implemented. The complexity and cost of the system can be reduced by eliminating the gas/liquid separator and the external pump. Without the external fuel pump, significant portion of power consumption on fuel delivery (estimated to be more than $10 \%)$ can be saved. The fuel circulation has been verified both visually and by confirming the self-sustainability of the fuel cell.

\section{ACKNOWLEDGEMENT}

The authors would like to thank Professor C.-M. Ho, Dr. T. Cubaud and Dr. T. J. Yen for their discussions and suggestions, as well as Mr. J. Jenkins and Ms. A. Lee for the help with the manuscript.

\section{REFERENCES}

[1] E. Sakaue, "Micromachining/Nanotechnology in Direct Methanol Fuel Cell," Proc. IEEE Int. Conf. Micro Electro Mechanical Systems, Miami, FL, 2005, pp. 600-5.

[2] MTI micro fuel cell: "http://www.mtimicrofuelcells.com/".

[3] IBM \& Sanyo's $\mu$ DMFC: "http://www.ibm.com/news/be/en/2005/04/11.html".

[4] Toshiba's $\mu$ DMFC: "http://www.toshiba.co.jp/about/press/2004 06/pr2401.htm".

[5] K. Yoshida, Y. Hagihara, S. Tanaka, and M. Esashi, "Normally-Closed Electrostatic Micro Valve with Pressure Balance Mechanism for Portable Fuel Cell Application," Proc. IEEE Int. Conf. Micro Electro Mechanical Systems, Istanbul, Turkey, Jan. 2006, pp. 722-5.

[6] D. D. Meng, J. Kim, and C.-J. Kim, "A degassing plate with hydrophobic bubble capture and distributed venting for microfluidic devices," Journal of Micromechanics and Microengineering (to appear), 2006.

[7] D. D. Meng and C.-J. Kim, "Micropumping by Directional Growth and Hydrophobic Venting of Bubbles," Proc. IEEE Int. Conf. Micro Electro Mechanical Systems, Miami, FL, Jan. 2005, pp. 423-6.

[8] D. D. Meng, T. Cubaud, C.-M. Ho, and C.-J. Kim, "A Membrane Breather for Micro Fuel Cell with High Concentration Methanol," Tech. Dig. Solid State Sensor, Actuator and Microsystems Workshop, Hilton Head Island, SC, Jun. 2004, pp. 141-4.

[9] D. D. Meng and C.-J. Kim, "Method and Apparatus for Pumping Liquids Using Directional Growth and Elimination of Bubbles." U.S. Patent pending: 60/647,139, 2006.

[10] U.-C. Yi and C.-J. C. Kim, "Soft Printing of Droplets PreMetered by Electrowetting," Sensors and Actuators A, 2004, vol. 114, pp. 347-54.

[11] D. D. Meng and C.-J. Kim, "Self-aligned Micro Bubble Arrays by Using Surface Tension," 2004 ASME Int. Mechanical Engineering Congress and Exposition, Anaheim, CA, Nov. 2004, CD: IMECE 2004-62182. 